\title{
EXPERIMENTAL AND NUMERICAL ANALYSES ON SANDSTONE ELEMENTS OBTAINED BY 3D PRINTING
}

\author{
C. SCURO $^{1 *}$, S. TIBERTI ${ }^{2}$, S. PORZIO ${ }^{3}$, R. S. OLIVITO ${ }^{3}$ AND G. MILANI $^{2}$ \\ ${ }^{1}$ Department of Physics \\ University of Calabria, Rende, Cosenza, Italy \\ E-mail: carmelo.scuro@unical.it (*corresponding author) \\ ${ }^{2}$ Department of Architecture, Built Environment and Construction Engineering \\ Technical University of Milan, Italy. \\ Email: simone.tiberti@polimi.it; gabriele.milani@polimi.it \\ ${ }^{3}$ Department of Civil Engineering \\ University of Calabria, Rende, Cosenza, Italy \\ E-mail: saverio.porzio@unical.it; renato.olivito@unical.it
}

Keywords: Historical Structure, Masonry, Monitoring, Non-Destructive Inspection

\begin{abstract}
The international cultural and historical heritage is often subject to degradation and damage. The main causes contributing to these phenomena are the chemical and mechanical actions due to acid rain, environmental pollution, and earthquakes. Other causes are the cycles of freezing and thawing that induce the manifestation of internal stresses leading to the deterioration of the material and the collapse of structural parts.

In the field of architectural restoration, this problem has been addressed by two main solutions. The first involves cleaning processes that leave the missing parts visible; the second consists of introducing reproductions of the missing parts, creating a clear distinction between pre-existing and new elements. In both cases, the seismic behavior of the structure is modified; in the second solution, the added elements do not contribute to the structural strength since they are made of plaster or stucco.

This work aims at presenting a preliminary study on the creation of replacements of missing elements within damaged heritage buildings. The work is structured in two distinct phases. In the first phase, specific cubic specimens, created with a $3 D$ printer, are produced and subjected to uniaxial compression tests. The experimental campaign is carried out in order to provide useful information regarding the $3 D$ material engineering constants that are currently absent in the literature. In the second phase, the experimental results are used in a numerical model to calibrate the mechanical properties of an equivalent homogeneous material.
\end{abstract}




\section{INTRODUCTION}

Masonry buildings constitute the largest part of the existing historical heritage. These structures often consist of materials with poor mechanical properties, since they date back to different historical periods. Several monumental masonry buildings are still standing despite being located in renowned seismic areas (in Southern Europe and especially in Italy); therefore, such buildings are characterized by a high level of seismic vulnerability. Currently, masonry buildings that are historically and culturally important are safeguarded by specific technical standards aiming at their protection and preservation over time [1-2]. Several detailed and advanced methods have been developed by researchers and engineers alike to investigate these buildings in the knowledge phase, for the assessment of their structural safety against seismic actions, and eventually for enacting possible strengthening and conservation strategies [3].

The cultural and historical heritage is often subject to degradation and damage inducted by the earthquakes and the kinematic mechanisms caused by these phenomena. However, such kind of damage is not the single reason behind the collapse of masonry structures. In fact, other causes can be identified in the chemical and mechanical actions due to acid rain, environmental pollution, and the cycles of freezing and thawing that produce internal stresses leading to the deterioration of the material and the collapse of structural parts [4]. This entails a reduction of the walls' thickness and, subsequently, of the overall structural strength; therefore, a strategy for replacing the missing structural parts must be conceived.
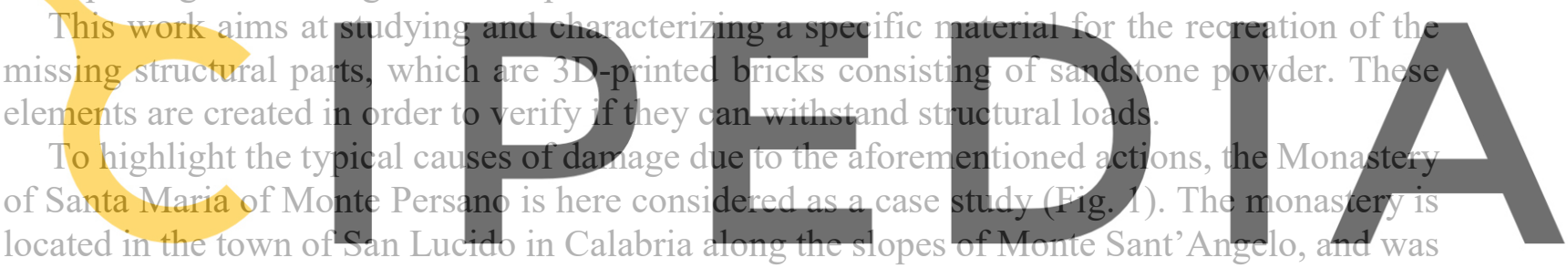
ostensibly established around the year 1000 by Basilian monks wandering in Southern Italy

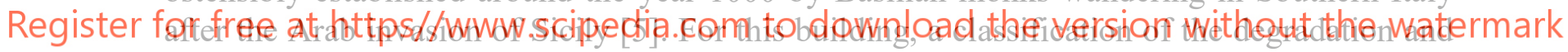
of the collapse mechanisms observed in the structure are carried out.

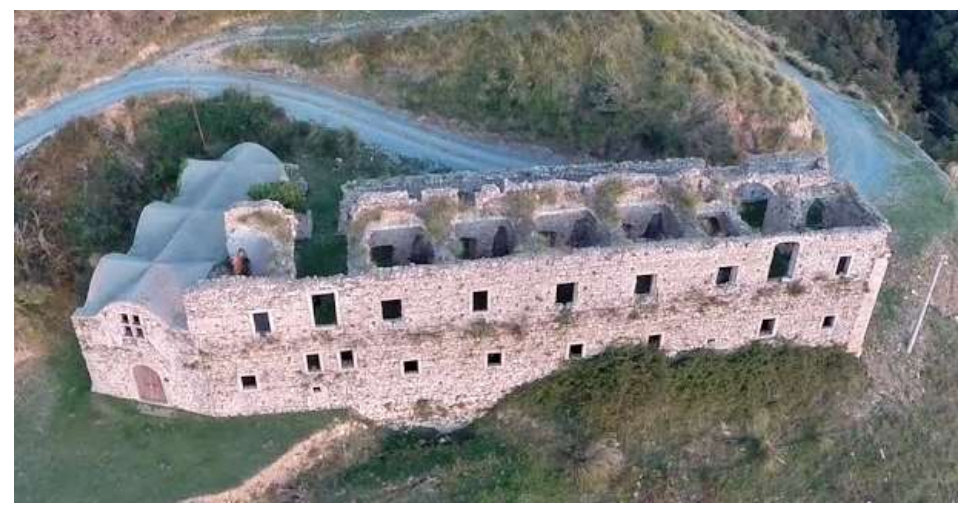

a)

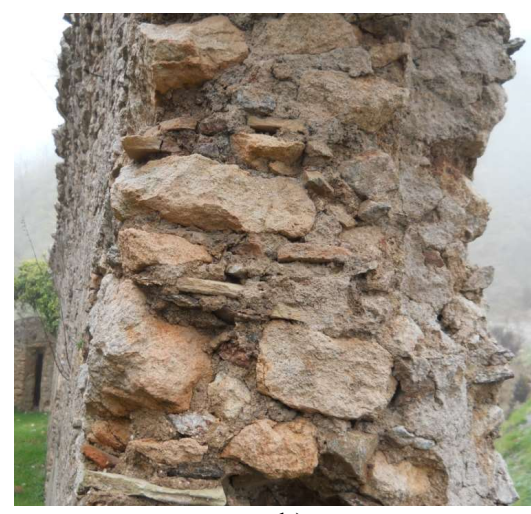

b)

Figure 1: a) Monastery of Santa Maria of Monte Persano; b) Masonry observed in the construction. 


\section{CLASSIFICATION OF THE DEGRADATION}

The classification of the structure degradation is carried out according to the Italian standard NorMal 1/88, produced by NorMal committee under the auspices of the CNR [6].
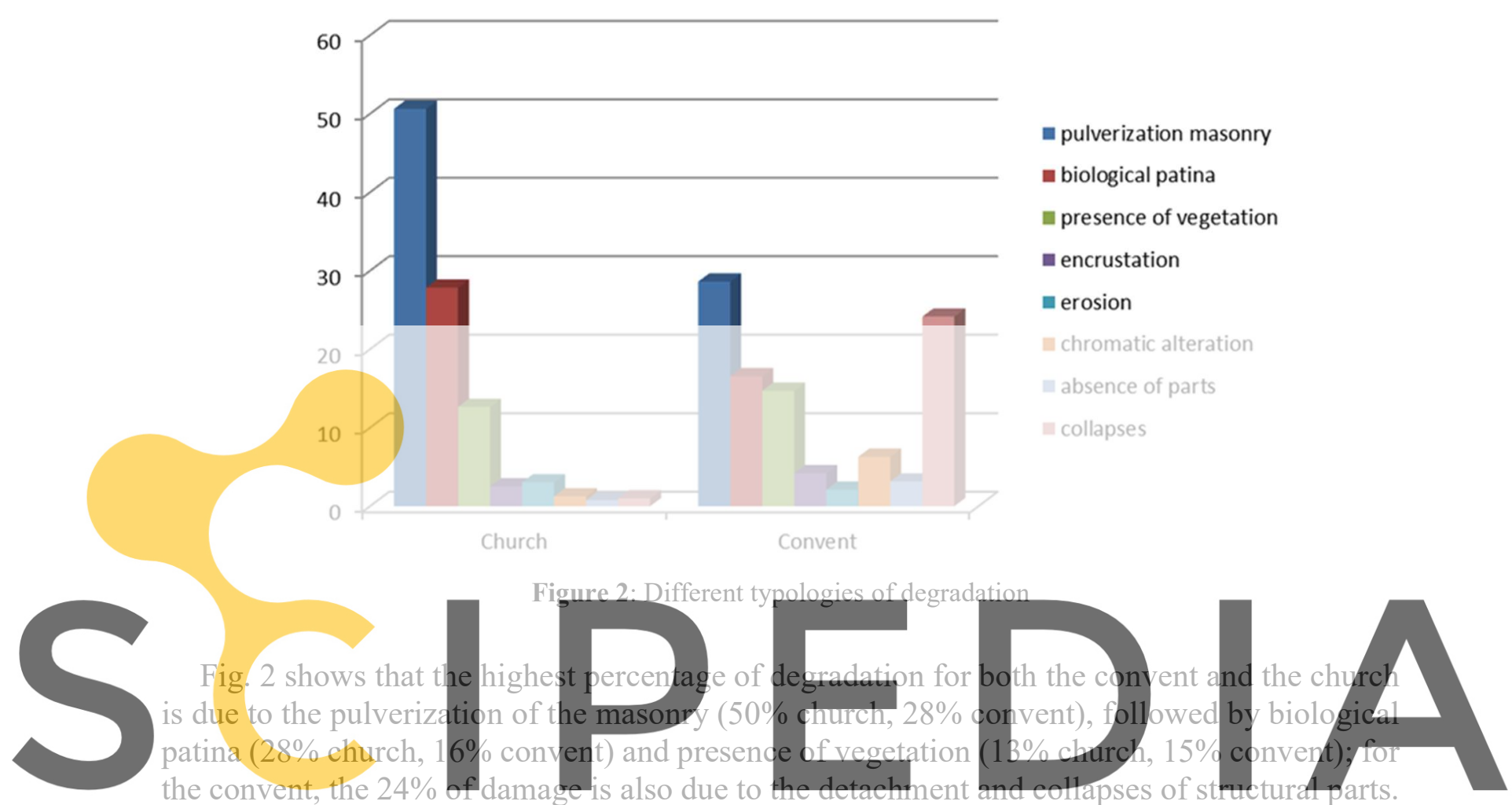

The action of water and weathering is a major cause of almost all degradation phenomena

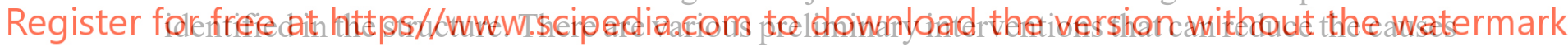
of these phenomena, canceling the capillary action of water by reducing its damaging effects on the masonry. For example, the removal of the biological patina can be achieved by applying - up to total absorption - an organic water-repellent solvent in conjunction with biocide herbicides [4].

The complex of Santa Maria is subject to static instability and is characterized by cracks located in some parts of the masonry walls. Apparent damage is observed in the openings, the transverse walls and the vaults of the church, which consist of fictile tubules [7-9]. Moreover, clear detachment cracks can be identified between some vertical elements and their related horizontal elements, which instead have remained intact over time. In general, all these cracks are related to static and seismic phenomena to which the building has been subject over the centuries. Overloads caused by the presence of material due to various collapses of the structure has created widespread damage on the most rigid walls and on the horizontal structures connected to them.

The church façade shows cracks on the vaults and in its square window, creating damage even on the lithic cross; other cracks affect the intrados of the vaulted roof. Conversely, the monastery displays widespread damage in the Southern façade above the main entrance, located 
under the window and positioned to the East. This type of damage tends to occur where the wall is weakened by the presence of irregular window holes (as in this case) due to the reduction in thickness of the wall of the sub-window. On the Western side of the same façade, a crack has developed from the inside (through-cracking), caused by the outer wall within the longitudinal rotation mechanism of the convent.

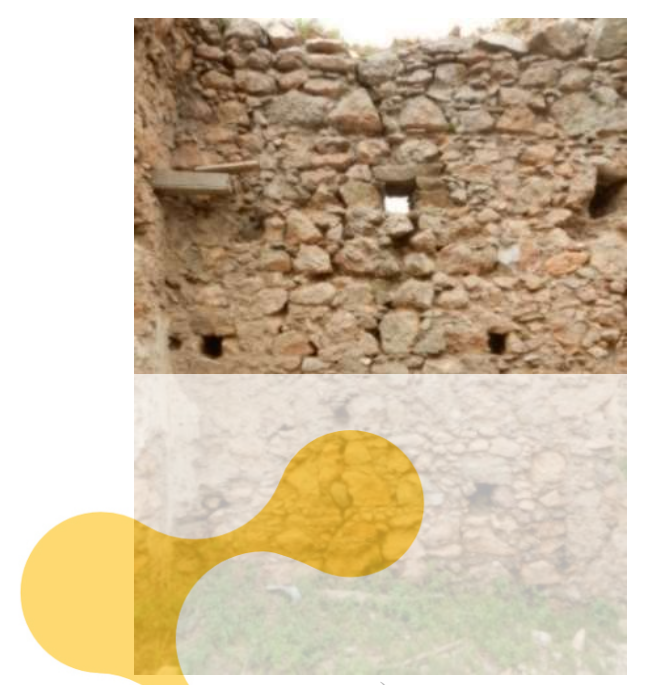

a)

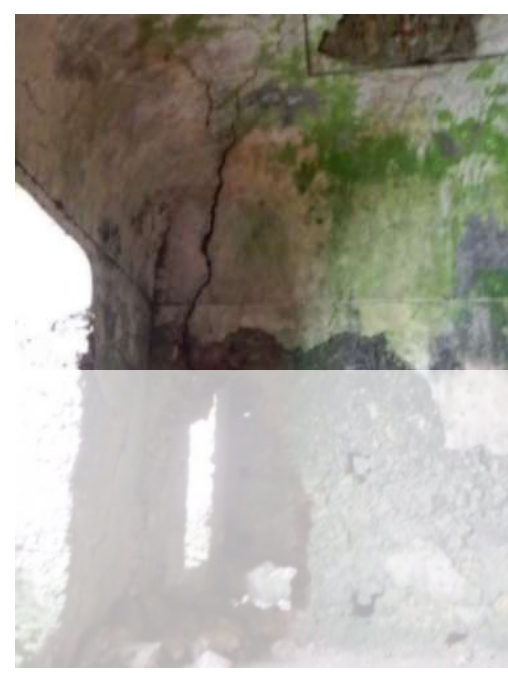

b)

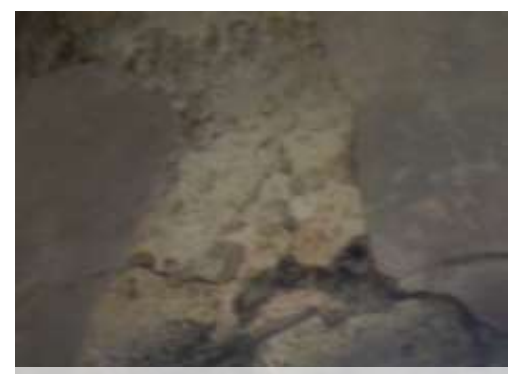

Figure 3 : a) Crack in th

Other damage can be identified in the dividing the various rooms (Fig. 3a), two are past (Fig. 3b), and five more appe

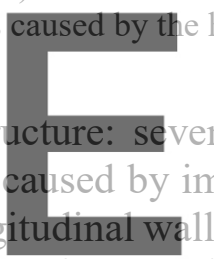

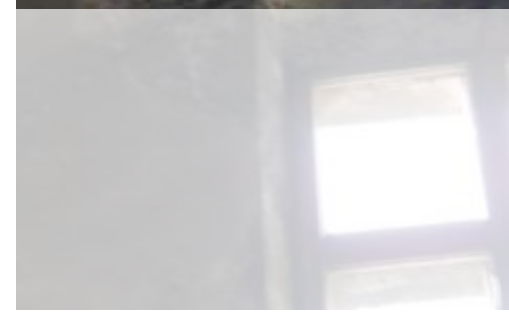

c)

In the ground floor there are other cracks: two again caused by the aforementioned holes, other

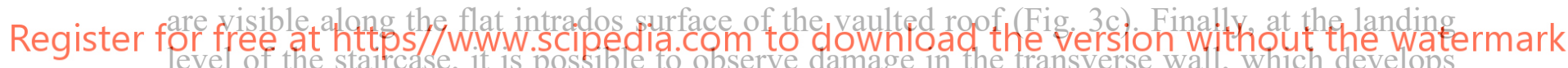
level of the stallcase, it is possible to observe damage in the transverse wall, which develops

from the bottom with a vertical progression and then is tilted.

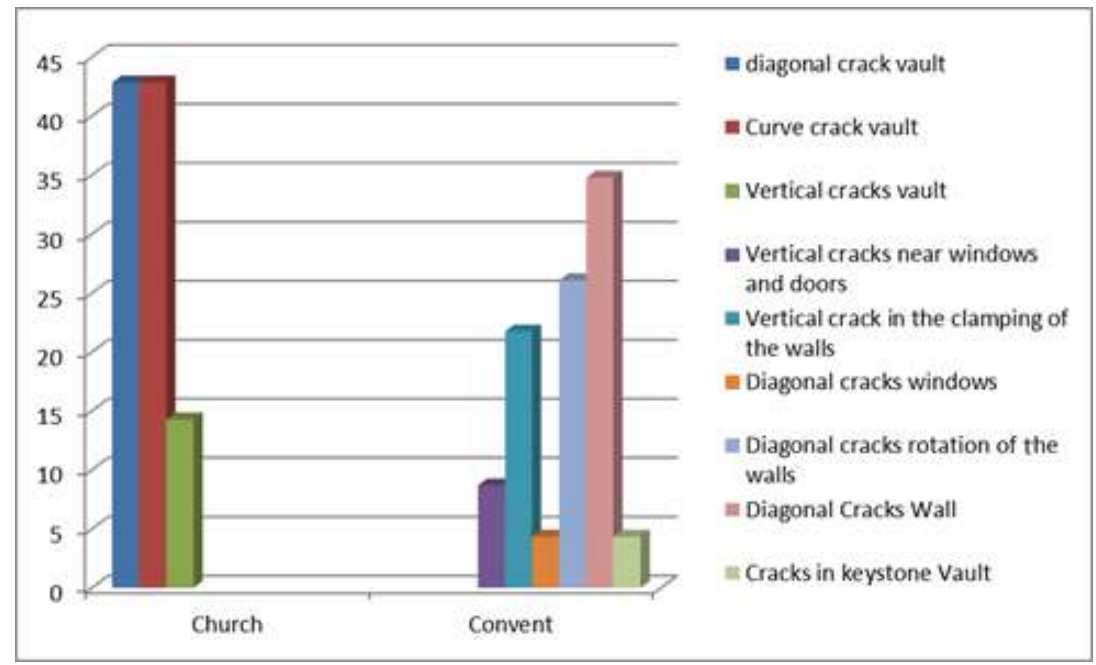

Figure 4: Different typologies of cracks. 
Fig. 4 shows the classification of the almost 30 cracks clearly identified in the structure. The church displays in percentage an equal amount of diagonal and curved cracks, the latter located in correspondence of the vaulted roof but also visible on the façade, below the arch of the vault. Different types of failure are instead observed in the convent: the highest percentage belongs to cracks with diagonal development due to improper holes in the walls $(34.8 \%)$, whereas other relevant percentages belong to diagonal cracks due to the rotation of the walls $(26.1 \%)$ and to vertical cracks located at the clamping of the walls $(21.7 \%)$.

The walls consist of masonry with disordered sandstone elements (cobblestone and uneven stone), like the rest of the construction. Protruding stones are visible on the right side of the Southern façade of the monastery, suggesting the continuation of the building to the Eastern side. This is corroborated by the presence of two arches that are located on the Eastern perimeter wall, which together with the four round arches are assumed connected to a supposed cloister.

\section{DRINTER TECHNOI OGIFS}

The technologies and operating principles on which 3D printers are based were developed in the late 1980s by S. Scott Crump and the Stratasys Company, which he founded in 1989. The company began manufacturing machines for rapid prototyping, capable of producing real objects from three-dimensional CAD models. The main technologies used for 3D printing are three: Fused Deposition Modeling, StereoLitographic Apparatus, and Selective Laser Sintering [10]

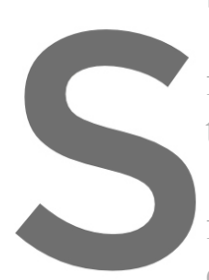

Fused Deposition ivio

for modeling and proto

then marketed by Strat

The technology operat

filament, collected in a

extruder nozzle onto the printing plate (bed),
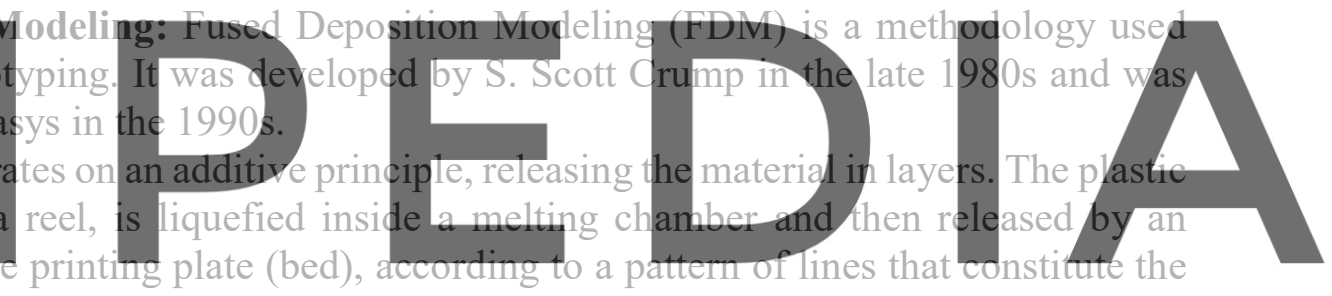

layers superimposed on the previous ones [11]. The nozzle, which is heated to dissolve the

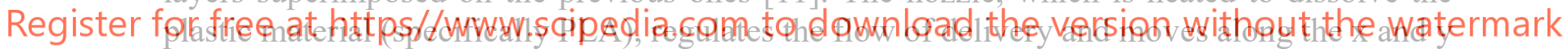

axes, guided by a numerical control mechanism, through the use of a CAM software (computeraided manufacturing) (Fig. 5a).

StereoLitographic Apparatus: The StereoLitographic Apparatus (SLA) represents the first technique adopted in rapid prototyping. It was created by Charles W. Hull, founder of 3D Systems and inventor, among other things, of the STL format (STereo Lithography interface format or acronym for "Standard Triangulation Language").

This technique uses a tank containing a special liquid resin capable of polymerizing when hit by light (photopolymerization); the printing plate, called bed, is the surface designed to accommodate the resin and is able to move up and down. A laser beam is projected through a system of mirrors, which shapes the liquid surface and modulates a raster image that is used to reconstruct the first section of the object to be created [10-11]. After the first scan, the bed lowers so that the resin can create a new liquid surface and a subsequent laser scan generates a second section (Fig. 5b). The process is repeated until the desired object is completed.

Selective Laser Sintering: Selective Laser Sintering (SLS), is based on the use of powders that can be thermoplastic, metallic or siliceous. The sintering of the powders, i.e. the compaction and transformation into an indivisible compound, takes place through a laser, thus 
generating the prototype to be printed.

The procedure involves spreading a thin layer of powder on the bed, using a special apparatus; at the same time, the laser sinters where necessary. Also in this case the bed is mobile, and lowers down to the desired level to distribute the next layer of powder; everything is repeated until the complete generation of the model. SLS-printing technology is used both for the creation of aesthetic prototypes, with high levels of refinement and accuracy, and for the reasonably fast creation of functional objects [11].

This sintering technology allows the use of different materials, usually mixed with nylon, with which it is possible to obtain objects with different performances of strength, elasticity, and temperature resistance. Finally, after processing, the object is removed and separated from the non-sintered powders, which are partially or totally recovered and then reused in other printing processes (Fig. 5c).
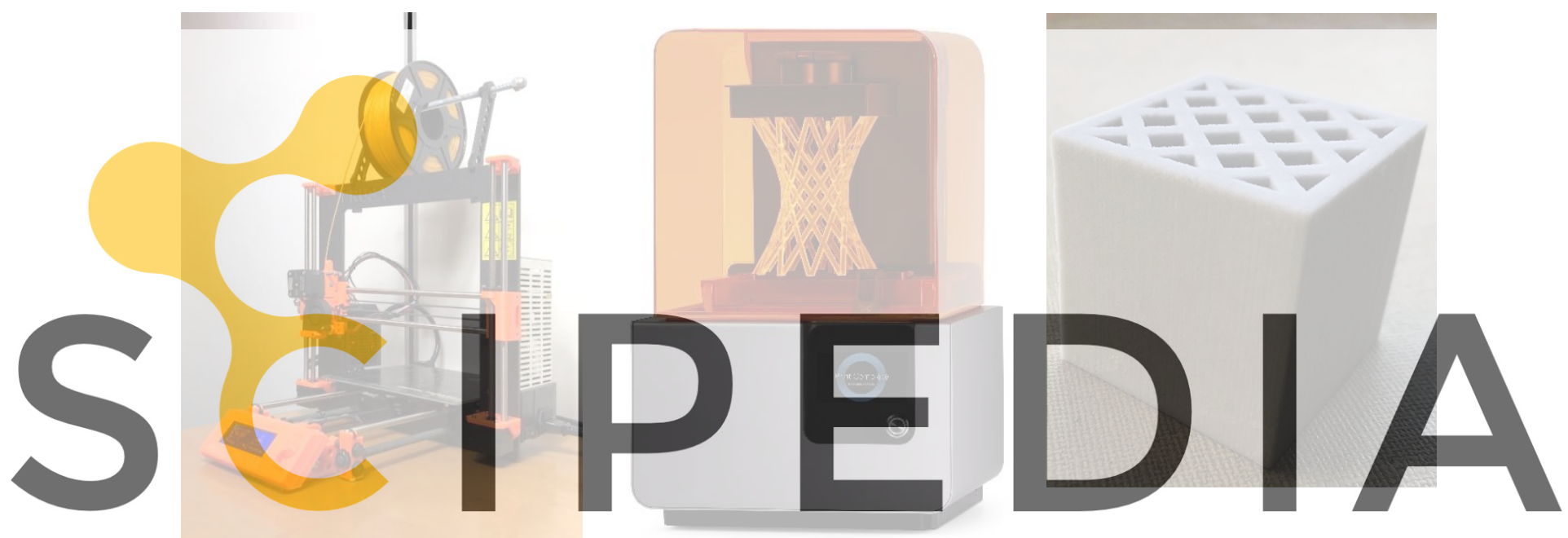

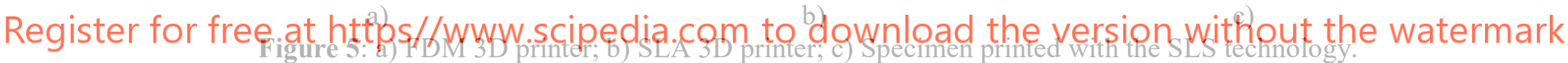

\section{EXPERIMENTAL CAMPAIGN}

In order to characterize the material used to create the elements, four specimens are 3Dprinted using the SLS technique. The samples are cubes with dimensions $40 \times 40 \times 40 \mathrm{~mm}^{3}$, and are characterized by a partially hollow internal conformation as shown in Fig. 5c. They are printed in this way to reduce costs and ensure lightness. The material used for rapid prototyping of the samples is laser sintered sandstone powder. This type of powder is chosen to ensure compatibility between the 3D-printed element and the support of the existing material in a typical masonry historical construction.

The aim of the experimental program is to investigate the mechanical properties of sandstone powder. All experimental tests are conducted at the Materials and Structures Engineering Laboratory of Civil Department of University of Calabria. The experimental mechanical properties here obtained are later used to calibrate the numerical model of the material. 


\subsection{Test set-up}

Uniaxial compression tests are performed on four cubic bricks printed in 3D NFTs (Fig. 6a). The testing machine used for the tests operates with a displacement control. The position and the lowering of the loading plate is provided at any instant and controlled through displacement sensors connected to the CPU of the test machine control panel [12]. Also, two strain gauges are applied on the lateral surfaces of the specimen to measure the values of vertical and horizontal strain [13] (Fig. 7b).

The compressive tests are performed with a crosshead speed equal to $0.2 \mathrm{~mm} / \mathrm{min}$; the load is applied parallel to the printed layers of the object.
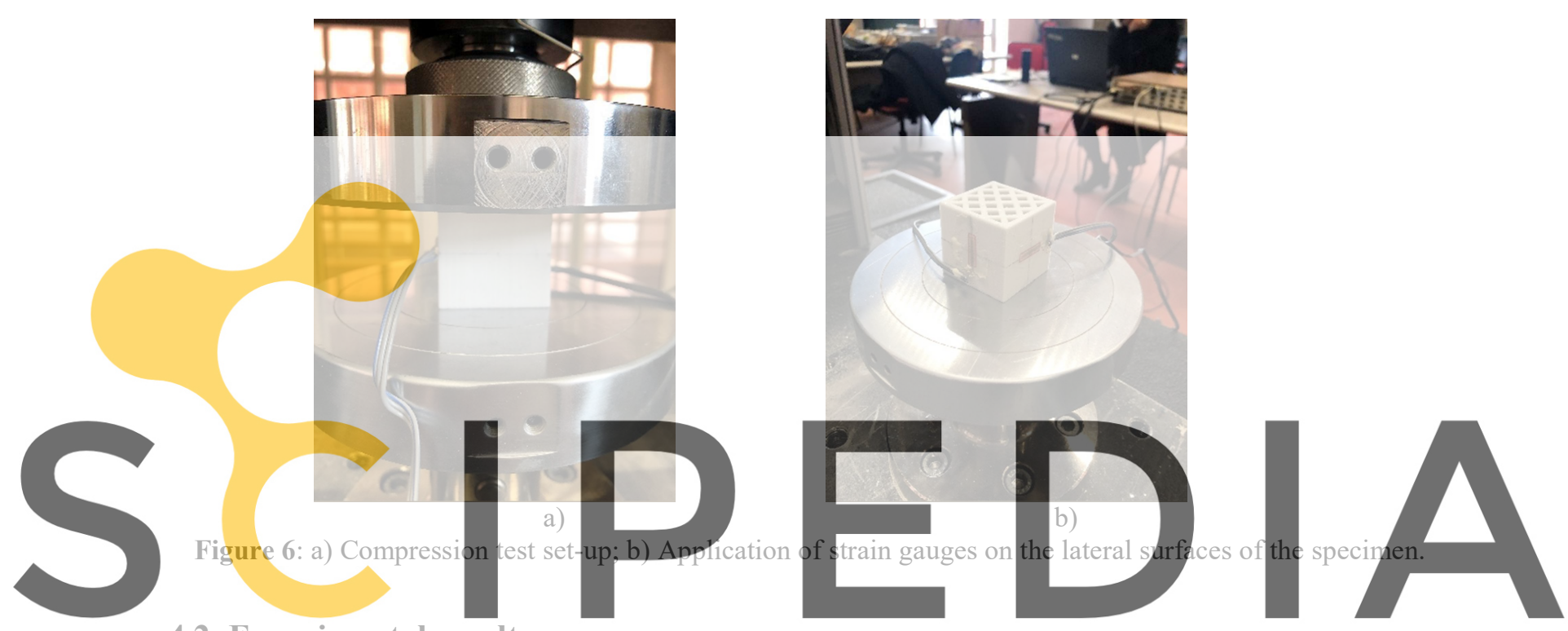

\subsection{Experimental resullts}

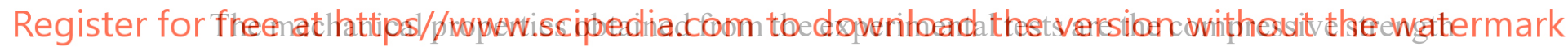
and Young's modulus of the 3D-printed cubic bricks. The load-displacement diagrams of the four compressive tests are plotted in Fig. 7. All specimens clearly display a brittle mechanical behavior with a strong linearity before attaining the peak load; the second part of the diagrams is characterized by a small softening branch. Also, the presence of strain gauges allows the evaluation of a constitutive law for the specimens. Fig. 8 shows the compressive stress-strain diagrams related to specimens.

The values of mechanical properties obtained from experimental tests are summarized in Table 1 and are in accordance with values available in literature for sandstone [14].

Table 1: Mechanical properties obtained from experimental tests

\begin{tabular}{cccc}
\hline Specimen & Peak load [kN] & Compressive strength [MPa] & Young's modulus [MPa] \\
\hline 1 & 45.04 & 39.25 & 5850.2 \\
\hline 2 & 39.39 & 34.33 & 5752.8 \\
\hline 3 & 38.87 & 33.87 & 8156.9 \\
\hline 4 & 35.82 & 31.21 & 7751.0 \\
\hline Average & 39.78 & 34.67 & 6877.7 \\
\hline
\end{tabular}




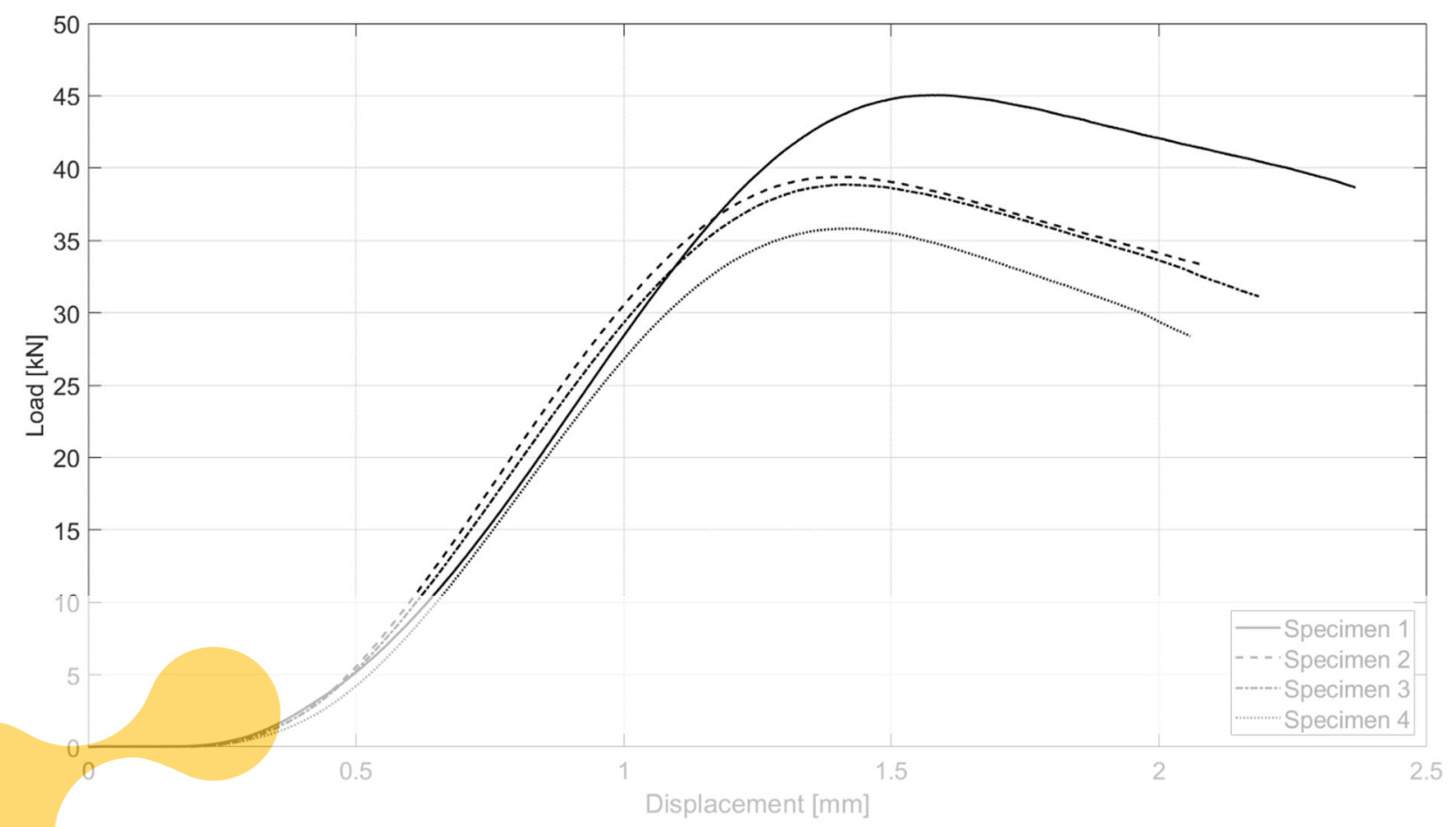

Figure 7: Load-displacement diagrams related to compressive test
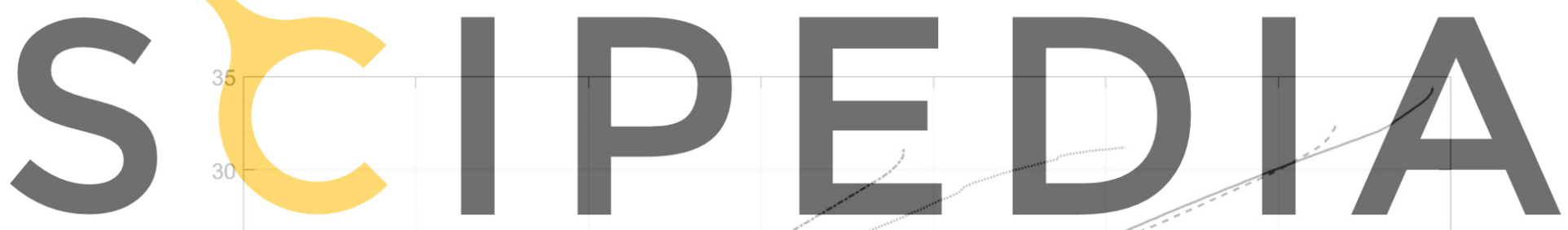

Register for free at https//www.scipedia.com to download the version without the watermark

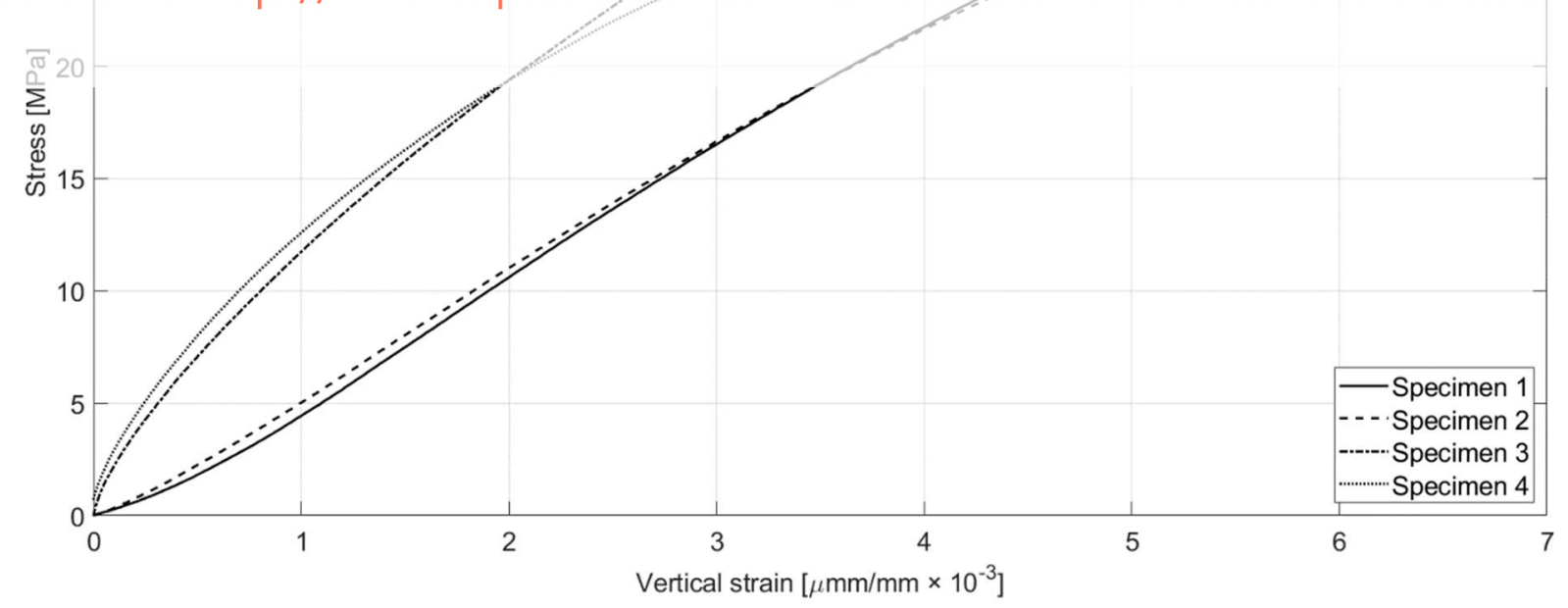

Figure 8: Stress-vertical strain diagrams related to compressive test 


\section{NUMERICAL MODEL}

The results obtained from the experimental campaign are used to calibrate the mechanical properties of an equivalent homogeneous material for use in advanced FE simulations. To this end, a numerical model of the specimen is created in the commercial FE code ABAQUS, sharing the same dimensions of the experimental cube $\left(40 \times 40 \times 40 \mathrm{~mm}^{3}\right)$ but with no holes. The exclusion of the voids from the numerical model is needed for calibrating the mechanical properties of the equivalent homogeneous material, which accounts for the presence of the voids only from a mechanical point of view, thus without modelling each of them. Then, a finite element mesh is created for the numerical model, consisting of 6773 quadratic tetrahedral elements as shown in Fig. 9.
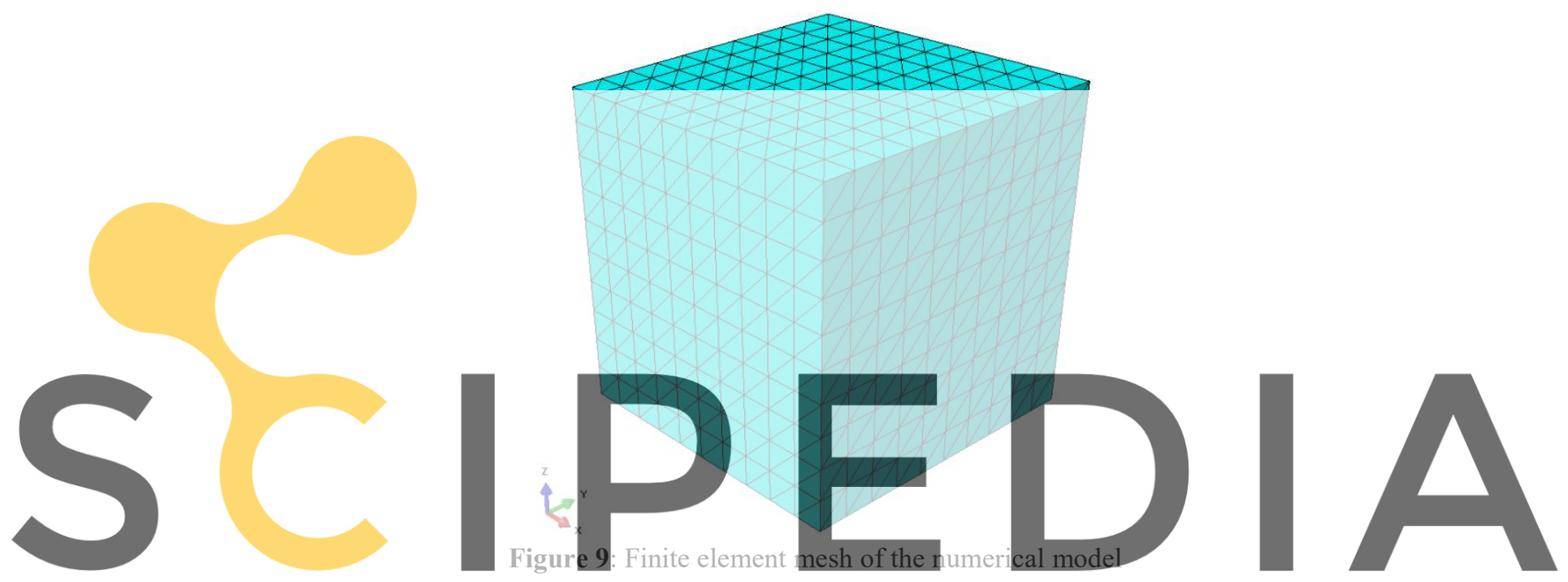

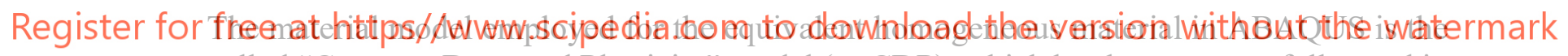
so-called "Concrete Damaged Plasticity" model (or CDP), which has been successfully used in several applications for representing the mechanical behavior of homogeneous materials due to its great versatility [8]. Here, the mechanical properties of the equivalent homogeneous material are calibrated by performing a series of numerical analyses simulating the experimental compressive test; the mechanical properties employed in the CDP are changed for every analysis until the resulting load-displacement diagram of the numerical compressive tests is contained in the envelope of the experimental ones. For both the compressive and tensile constitutive laws of the equivalent homogeneous materials, an exponential decay law is defined starting from the values of compressive and tensile strength, respectively.

The final result shows that the value of the Young's modulus found in the experimental campaigns can be safely used for the equivalent homogeneous material; the compressive strength must instead be reduced due to the fact that the numerical compressive test is performed on a full cube with no holes, where a larger area is involved in the application of the external load. The values of the mechanical properties of the calibrated equivalent homogeneous model are listed in Table 2. Fig. 10 shows the load-displacement diagram of the numerical model with the calibrated mechanical properties plotted against the envelope of experimental data, where it fits rather satisfactorily. 
Table 2: Mechanical properties of the calibrated equivalent homogeneous model

\begin{tabular}{cccc}
\hline $\begin{array}{c}\text { Young's modulus } \\
{[\mathrm{MPa}]}\end{array}$ & Poisson's ratio [-] & $\begin{array}{c}\text { Compressive strength } \\
{[\mathrm{MPa}]}\end{array}$ & $\begin{array}{c}\text { Tensile strength } \\
{[\mathrm{MPa}]}\end{array}$ \\
\hline 6878 & 0.29 & 24.5 & 2 \\
\hline
\end{tabular}

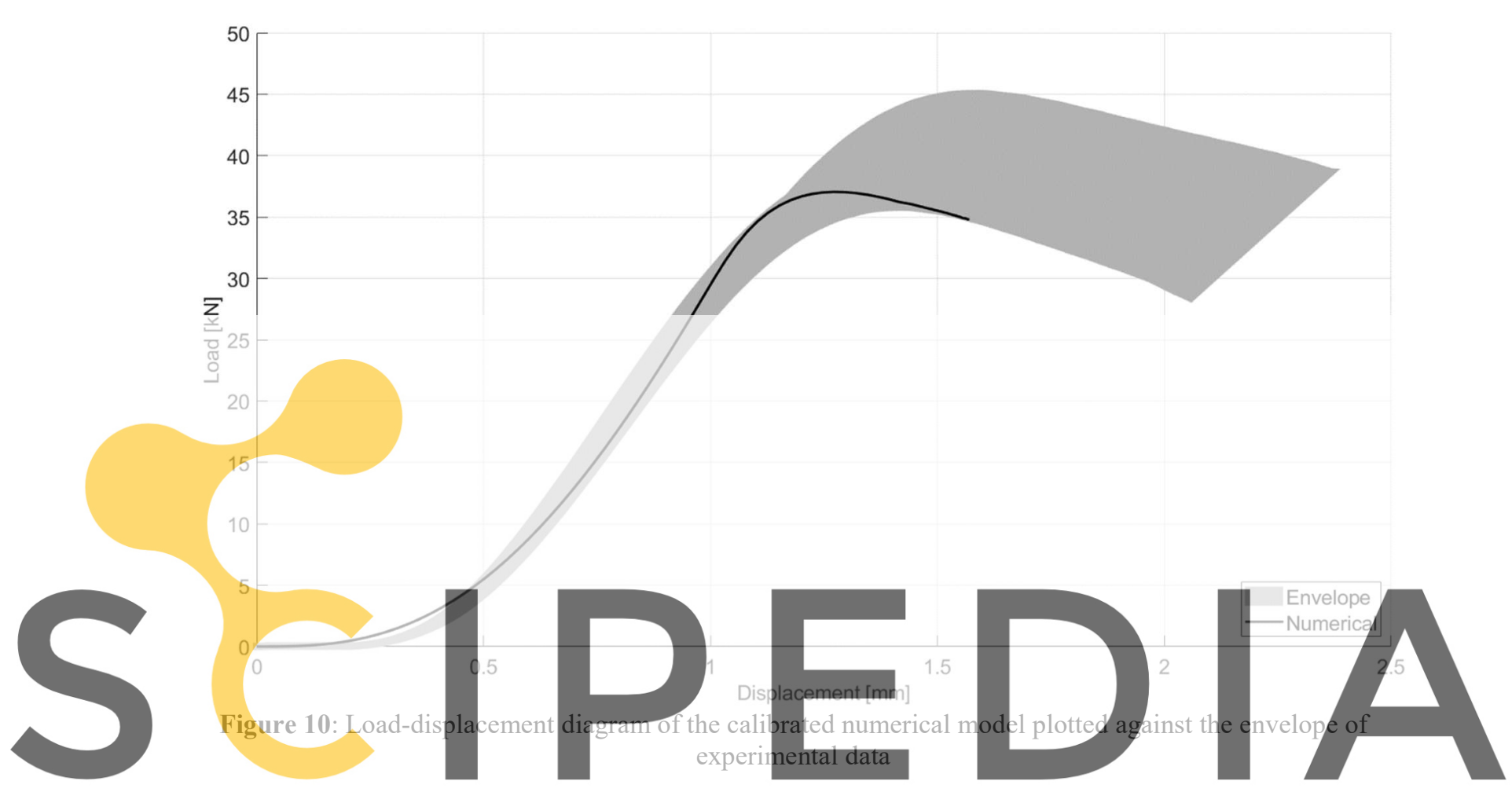

Register for free at https/ywww.scipedia.com to download the version without the watermark

Safeguarding and rehabilitating the Italian cultural and historical heritage is one of the most important issues to address in the context of structural engineering. To date, many structures in the historic centers are degraded and damaged, and often this damage is not only due to seismic actions but also to different factors such as the chemical and mechanical actions induced by acid rain, environmental pollution, and the cycles of freezing and thawing. One of the main consequences is usually the partial collapse of structural elements and the reduction of their mechanical properties.

The main purpose of this paper is to find a solution to this problem. A 3D model is created in a computer graphics software and is subsequently prototyped with a printer employing the SLS technology. The four specimens are subjected to compressive tests to identify their compressive strength and Young's modulus, which are still not available in literature for structural elements created with sandstone powders. The average values obtained from the experimental campaign are $34.67 \mathrm{MPa}$ and $6877.7 \mathrm{MPa}$ for the compressive strength and Young's modulus, respectively. These values are in accordance with those typically found in the literature for classical sandstone, and highlight how the structural elements made with this technique can both replicate the absences in the structure and resist the applied loads. The 
experimental data are eventually used to calibrate numerically the mechanical properties of an equivalent homogeneous material that can be used in ABAQUS to reproduce those of the 3Dprinted material. This is achieved by performing numerical analyses of the experimental compressive tests on an analytical model of the specimen, tuning the mechanical properties of the equivalent homogeneous material until the numerical load-displacement diagram fits well into the envelope created from the experimental data. The mechanical properties obtained through this calibration can then be used in advanced numerical analyses to simulate the presence of the 3D-printed material in complex analytical models where this material is used to recreate missing structural parts.

\section{REFERENCES}

[1] Olivito, R. S., Codispoti, R., \& Scuro, C. A seismic analysis for masonry constructions: The different schematization methods of masonry walls. In AIP Conference Proceedings (Vol. 1906, No. 1, p. 090007). AIP Publishing, (2017, November).

[2] Tiberti, S., Scuro, C., Codispoti, R., Olivito, R. S., \& Milani, G. Experimental and numerical analysis of historical aseismic construction system. In Structural Analysis of Historical Constructions (pp. 910-918). Springer, Cham. (2019).

[3] Olivito, R. S., Scuro, C., Porzio, S., Codispoti, R., \& Demarco, F. Seismic vulnerability of ancient masonry buildings: The case study of low-rise towers. In AIP Conference Proceedings (Vol. 2116, No. 1, p. 420007). AIP Publishing LLC. (2019, July).

[4] Croci, G. The conservation and structural restoration of architectural heritage, Vol. 1 (1998). WIT Press.

[5] Martire D. La Calabria sacra e profana. (1878). Tip. Migliaccio.

[6] NorMal 1/88, CNR Italy.

[7] Scuro, C., Lamonaca, F., Codispoti, R., Carnì, D. L., \& Olivito, R. S Experimental and numerical analysis on masonry arch built with fictile tubules bricks. Measurement. (2018), 130, 246-254.

[8] Scuro, C., Tiberti, S., Codispoti, R., Milani, G., \& Olivito, R. S. Fictile tubules: A traditional Mediterranean construction technique for masonry vaulted systems. Construction and Building Materials, (2018). 193, 84-96.

[9] Scuro, C., Tiberti, S., Porzio, S., Olivito, R. S., \& Milani, G. (2019, August). Study of the interface behaviour between fictile tubules bricks and mortar: numerical and experimental analysis. In IOP Conference Series: Materials Science and Engineering (Vol. 586, No. 1, p. 012027). IOP Publishing.

[10] Schubert, C., Van Langeveld, M. C., \& Donoso, L. A. Innovations in 3D printing: a 3D overview from optics to organs. British Journal of Ophthalmology, (2014), 98(2), 159161.

[11] Calignano, F., Manfredi, D., Ambrosio, E. P., Biamino, S., Lombardi, M., Atzeni, E., ... \& Fino, P. Overview on additive manufacturing technologies. Proceedings of the IEEE, (2017).105(4), 593-612.

[12] Tiberti, S., Scuro, C., Codispoti, R., Olivito, R. S., \& Milani, G. Traditional masonry arches and domes with fictile tubules in mediterranean seismic areas: advanced numerical models and experimentation. In 6th ECCOMAS thematic conference on computational methods in structural dynamics and earthquake engineering, Rhodes Island, Greece 
(2017, June) (pp. 2431-2448).

[13] Scuro, C., Sciammarella, P. F., Lamonaca, F., Olivito, R. S., \& Carni, D. L. IoT for structural health monitoring. IEEE Instrumentation \& Measurement Magazine, (2018). 21(6), 4-14.

[14] Molina, O., Vilarrasa, V., \& Zeidouni, M. Geologic carbon storage for shale gas recovery. Energy Procedia, (2017)114, 5748-5760. 